\title{
EUGENIO MARÍA DE HOSTOS ANTE EL CONFLICTO MODERNISMO/MODERNIDAD
}

\author{
POR \\ ALFREDO VILLANUEVA-COLLADO \\ Eugenio María de Hostos Community College
}

Para quienes se ocupan de estudiar el desarrollo cul tural de Hispanoamérica, particularmente el momento finisecular, la aparición del Modernismo como movimiento literario, y la creación ideológica por parte de la crítica de rangos de escritores -estrellas como Darío y Martí, escritores de segunda fila, como José Asunción Silva, y finalmente aquéllos a los cuales se deja fuera del canon, como a Vargas Vila- les es muy importante aclarar y delimitar los términos utilizados, para evitar posturas hegemónicas tales como las que se han dado hasta ahora. Giovanni Allegra apunta en tal dirección al señalar que el modernismo - como serie de pautas estéticas — se opone a la modernidad como serie de pautas socioeconómicas. ${ }^{1}$ Ya que son los pensadores sociales de la época los que producen las normas con las cuales se intenta construir una cultura hispanoamericana adscrita al ideal del "progreso", he escogido la figura de Eugenio María de Hostos y he intentado situarlo con respecto al conflicto Modernismo/Modernidad -el primer término entendido estéticamente y el segundo sociológicamente. Deseo también colocar ambos conceptos dentro del marco ideológico que los produce e intentar elucidar qué tipo de ideología determinan los comentarios de Hostos en materia de música, escultura, pintura y poesía.

Richard Terdiman explica que la ideología se manifiesta en dos tipos de discurso. El discurso dominante expresa valores sociales y culturales, caracterizándose por la imposibilidad social de su ausencia. ${ }^{2}$ Un discurso tal aparece en todas partes pero parece no tener origen en ninguna, y permea el cuerpo social de tal manera que cualquiera que intente oponerse debe de utilizarlo. Cada discurso dominante produce un contra/discurso constituido

\footnotetext{
1 Giovanni Allegra, Del modernismo como antimodernidad (Bogotá: Instituto Caro y Cuervo, 1981).

${ }^{2}$ Richard Terdiman. Discourse /Counterdiscourse: The Theory and Practice of Symbolic Resistance in Nineteenth Century France (Ithaca and London: Cornell University Press, 1985) 61. Éste y otros materiales que utilizo en este ensayo han sido utilizados previamente; la traducción es mía.
} 
como su opuesto. Su función es señalar las fallas y límites del discurso dominante. Puede que existan varios contradiscursos operando simultáneamente, pero lo único que tienen en común es la posición adversaria que asumen. El tono caracteristico del contradiscurso es la ironía corrosiva en cuanto al aquí y al ahora, (Terdiman 76), y su meta es una representación alterna de la realidad social. El poder del discurso dominante reside en los códigos mediante los cuales regula la comprensión del cuerpo social. ${ }^{3} \quad$ El contradiscurso detecta tales protocolos y los subvierte (Terdiman 149). Finalmente, Terdiman indica que, ya que el contradiscurso se constituye en oposición al discurso dominante, paradójicamente reafirma la posición privilegiada de éste -el contradiscurso termina por reflejar los términos ideológicos de los cuales quiere liberarse.

La modernidad se representa como discurso dominante; el Modernismo, su contradiscurso. Terdiman identifica la ideología que le da origen como "liberal". La ideología liberal proyecta la extinción gradual de diferencias individuales y de clase (Terdiman 48) y la creación del hombre masa, perteneciente a una clase universal, la clase media. El término utilizado implica ya una nivelización del sujeto, la eliminación de polaridades dentro de las estructuras sociales. No se trata aquí de la sociedad sin clases, meta del milenio marxista, sino de la creación de una clase de consumidores, guiada por lo que Erich Fromm ha llamado "instinto de rebaño", y para quienes la obra de arte, en lugar de existir como antes en situación privilegiada, ahora existe como producto, sujeta a leyes de mercado dentro de una economía capitalista. George L. Mosse explora otro aspecto de la aparición de la clase media como productora de discurso dominante en su estudio sobre el desarrollo conjunto de las nociones de nacionalismo, propiedad/impropiedad y anormalidad sexual en la Europa decimonónica. Señala Mosse que, a través de la creación de un código ético de conducta sexual, la clase media europea consigue diferenciarse tanto de las clases superiores como de las inferiores, ${ }^{4}$ y a través de la absorción de la conducta sexual dentro del concepto de nacionalismo (la patria), abre el camino para la persecución fascista del Otro, siempre concebido en términos de conducta sexual anormal. ${ }^{5}$

${ }^{3}$ Debo aclarar que percibo la critica literaria hispanoamericana como producto en su mayor parte de una clase burguesa compuesta de varones blancos de clase media, y por lo tanto como una modalidad de discurso dominante utilizado para crear una imagen oficial positiva de la cultura, que no siempre concuerda con la realidad social tal y como se encuentra expresada en obras artísticas - pero que el discurso dominante moldea y manipula a través de la creación de un canon literario.

4 George L. Mosse, Nationalism and Sexuality: Respectability and Abnormal Sexuality in Modern Europe (New York: Howard Fertig, 1985) 4.

${ }^{8}$ Mosse 24. A este respecto cabe preguntarse por qué la crítica literaria hispanoamericana nunca ha podido bregar con el contenido sexual de la cultura, y por ende de la literatura, y particularmente los contenidos homoeroticos. 
Se enmarca el discurso dominante de la modernidad en los conceptos de nacionalismo, respetabilidad y la creencia en el progreso, entendido primariamente como material y sólo luego como cultural o espiritual. Francia, Alemania, Inglaterra difunden el evangelio del progreso y la ideología del liberalismo. En un artículo reciente, ${ }^{6}$ he propuesto la existencia de un segundo proceso colonizador que ocurre en Hispanoamérica, proceso mediante el cual los intelectuales que adoptan posturas progresistas en realidad se solidarizan con las premisas del nuevo discurso dominante creado por la clase media europea. Ello ocurre como reacción al estatus colonial de Hispanoamérica bajo la corona española. Los ingleses, los alemanes, y más tarde los norteamericanos, sirven de modelos para la nueva sociedad que estos individuos desean en el futuro de Hispanoamérica.

Por otro lado, la modernidad artística, o Modernismo, refleja una realidad social muy diferente. Los adelantos tecnológicos han enajenado al hombre de su medio ambiente en términos de tiempo y espacio. La luz eléctrica prolonga el día indefinidamente y destruye para siempre la noción de claroscuro; el cine, por medios técnicos, elimina la noción de secuencia cronológica. ${ }^{7}$ Se normatiza el tiempo público; el reloj de bolsillo se convierte en objeto indispensable y la puntualidad en virtud pública. ${ }^{8}$ Se crea el concepto del tiempo privado (Kern 33). Ya en 1884, William James caracteriza el tiempo como fluir de conciencia, lo cual lo deconstituye en términos de realidad externa y lo reconstituye en terminos de la psique (Kern 24).

La percepción de la simultaneidad de espacios -ya dada la uniformidad del tiempo- lleva a la destrucción de jerarquías tradicionalmente verticales, a la reconstrucción de la realidad de acuerdo al perspectivismo (Kern 131) y al concepto, originalmente pictórico, del espacio positivo/negativo. En pintura, se concibe al sujeto como espacio positivo y al trasfondo como espacio negativo. La nueva percepción del espacio da igual valor a ambos, aboliendo la diferencia entre elementos primarios y secundarios. Tal cambio constituye una alteración fundamental de las premisas metafísicas del pensamiento occidental (Kern 152-53). En términos de historia de las ideas, hay que considerar el hecho de que Lenin rechaza la transformación del tiempoy el espacio en categorías subjetivas desde el enfoque del materialismo histórico, para el cual es absolutamente necesario que exista una realidad objetiva en la cual se dé la lucha de clases y el advenimiento del milenio proletario (Kern 134).

\footnotetext{
'Alfredo Villanueva-Collado, "Ideología y política: José Asunción Silva y la corrupción de la semilla histórica de 'De sobremesa', Discurso Literario 6 (otoño 1988) 255-266.

${ }^{7}$ Stephen Kern. The Culture of Time and Space 1880-1918 (Cambridge, MA: Harvard University Press, 1983) 29, 70.

${ }^{8}$ Kern 110. Hay que reflexionar, entonces, qué significa pertenecer a una sociedad que se asocia culturalmente con el hábito de "llegar tarde", señal segura, para los productores del discurso dominante, de subdesarrollo.
} 
Todo locual significa la aparición de una vanguardia, definida por Frederick Karl, para quien "la vanguardia ... es el momento en cada fase del Modernism en que lo moderno se da o expresa en su lenguaje particular .... La vanguardia es frecuentemente un nuevo tipo de orden". ${ }^{3}$ Mas un orden que intenta reflejar y llamar la atención sobre la dislocación del tiempo y el espacio, dislocación que se percibe como un desorden espiritual y cultural, una fragmentación de la realidad que sólo puede reconstituirse - y he aquí la idea clave-a través de la fragmentación del lenguaje en lenguajes. Éstos a su vez expresarán adecuadamente el hecho de que la nueva colectividad se compone de elementos heterogéneos, de jerarquías mutables $-\mathrm{y}$ cito de nuevo a Karl:

A medida que la realidad física se fragmentaba en pequeñas unidades, se descompuso el orden. La deconstrucción de la materia era paralela a la deconstrucción de la vida ordinaria. Se redujo y se desnudo al hombre para que fuera reconstituido de manera diferente, y se tenfan que inventar lenguajes, colores, y sonidos que así lo expresaran(Karl 100).

Por lo tanto, ocurre una "desaparición del discurso convencional"(Karl 139), ya que "el cambio de lenguajes se conecta a un cambio gradual de modos de percibir, verdaderos terremotos culturales"(Karl 7). Elénfasis en la originalidad, en el individuo, en la supremacía no de Dios sino del Ser, desplaza la experiencia comunitaria, y el lenguaje, cuya racionalidad se basaba en tal comunalidad, adquiere una función artificial. Los nuevos lenguajes dis/continuos sirven de base para los nuevos modos de percepción. Durante este período se enfatiza la "visión" o "percepción" y el papel que juega el "visionario" como transmisor de conocimiento (Karl 68). Ocurre una separación entre el lenguaje cotidiano y la vida interior que tal lenguaje se supone que refleje y exprese, lo cual implica que el lenguaje no puede comunicar lo "incomunicable"; pero aún mas, dado el hecho de que la palabra ha perdido valor como signo inmutable, ocurre un divorcio entre "lectura" y "escritura"(Karl 105).

En 1883, Paul Bourget define la forma en términos de estructuras narrativas, que toma el contradiscurso moderno de las artes:

Un estilo decadente es aquél en que se descompone la unidad del libro para dar paso a la independencia de la página, donde se descompone la página para dar paso a la independencia de la frase, y la frase para darle paso a la independencia de la palabra. ${ }^{10}$

John Reed señala que, en lo que respecta a las artes plásticas, ocurre el mismo énfasis en la estructura, no el contenido (Reed 128), mencionando que el

\footnotetext{
${ }^{9}$ Frederick Karl, Modern and Modernism: The Sovereignty of the Artist 1885-1925 (New York: Atheneum, 1985) 13.

10 John Reed, Decadent Style (Athens, OH: Ohio University Press, 1985) 10.
} 
estilo decadente, "aunque retiene un modo realista de presentar la imagen, viola las convenciones formales al romper la composición en partes independientes y aún contestatarias, el orden y el significado de las cuales sólo se puede recuperar a través de un esfuerzo intelectual" (Reed 129). La energía de tal estilo depende de "una tensión sin resolver, una exacerbación de los sentidos, una intelectualización de los motivos físicos" (Reed 130). Este arte nuevo rechaza los modelos naturales y trabaja desde la memoria y la imaginación (Reed 133). El arte es la expresión de una visión interior. Rodolfo Dresdin, artista gráfico admirado por Des Esseintes en A rebours, señala que "el artista no debe ni siquiera mirar en dirección a la naturaleza. Todo lo lleva dentro de si ${ }^{m}$ (Reed 152). Por otrolado, cuando percibe el medioambiente ylo encuentra contaminado por la modernidad cientifica y tecnológica, debe entonces aplicarle la "ironía corrosiva" para exponer sus fallas fundamentales. Reed resume tal estilo como "una aparente fragmentación en partes que atraen por sí mismas y sólo interpretables por medios Titerarios', ya narrativos, ya simbólicos" (Reed 184). Tal mezcla de técnicas tradicionales y nuevas funciona como modo de crear tensión.

En cuanto a la música y el contradiscurso moderno, Reed analiza una de las sonatas de Chopin, escrita para piano, y ofrece la opinión de un crítico contemporáneo del músico:

Chopin es incansable y debo decir inexhaustible en sus discordancias rompetímpanos, sus transiciones forzadas, sus modulaciones duras, sus horrendas distorsiones de melodía y ritmo. Utiliza todo lo que se puede utilizar para producir un efecto de extraña originalidad, pero sobre todo, notas extrañas y la más antinatural posición de acordes (Reed 191).

Cito este pasaje precisamente por su semejanza con la opinión que tiene Hostos sobre el piano como instrumento. Reed enfatiza el hecho de que la utilización, por parte de Chopin, de imbalance y asimetría -que llama "armonía grotesca" - se refleja después en la obra de Richard Wagner y Richard Strauss (Reed 195).

En cuanto a Wagner, señala Reed que su estilo es decadente porque se concentra en motivos atomísticos que, por su desarrollo entrelazado, subvierten la forma tradicional de la cual parecen ser los elementos, y en cambio crean una nueva forma más cerebral, que depende de la participación intelectual del público, ya que el sentido sólo se entiende cuando se entiende el simbolismo (Reed 206).

Debe ser obvio que para este momento he cambiado de términos: de la antinomia Modernidad/Modernismo he pasado a Modernidad científica/ Modernidad artística, antinomia que expresa, de forma más precisa, el conflicto entre el discurso dominante y el contradiscurso en términos de los cambios sociales que se efectúan a fines del Siglo XIX. El estilo decadente, tal y como lo define John Reed en sus diferentes modalidades, contiene el comentario "irónico 
corrosivo" de la modernidad artística sobre lo que la modernidad tecnológica, representada casi exclusivamente por las ciencias sociales, juzga ser el desarrollo inexorable de la humanidad: un mundo libre de los peligros de la imaginación y la metafísica, regido por leyes naturales y morales. Tales leyes, cuando se las somete al análisis de la ironía corrosiva, resultan ser nada más que artefactos ideológicos.

No se duda aquí de la sinceridad de pensadores tales como Hostos, quien respondió como se suponía que respondiese a las presiones de determinada circunstancia histórica. Pero tal respuesta lleva implícita la inscripción de un discurso dominante que consolida el poder hegemónico de la burguesía europea y norteamericana, y esparce una ideología que, si bien "superior" a la que ya se encontraba presente y, por lo tanto, tildada de "progreso", sirve sin embargo a un nuevo tipo de imperialismo, no geográfico, sino cultural. Quiero ahora pasar a las ideas de Hostos y su visión de mundo, que determina su percepción de las artes.

Carlos Rojas Osorio cita a Hostos en cuanto a su creencia de que la filosofía se funda en el estudio de la ciencia positiva y de que su unidad depende del rechazo de la metafísica. ${ }^{11}$ Tal rechazo es una de las razones fundamentales para la separación entre modernidades. Marta Aponte Alsina comenta acerca de la "conocida aversión" de Hostos hacia la literatura de la imaginación. ${ }^{12}$ Ésta es otra razón fundamental para los desacuerdos entre modernidades, como se evidencia en Degeneración (1892) de Max Nordau, quien propone que todos los grandes artistas modernos son degenerados mentales debido a un exceso de imaginación y un sistema nervioso enfermizo. Nordau también basa sus argumentos en la ciencia positiva. La metáfora orgánica, mediante la cual la imaginación puede ser catalogada como "enfermedad", está presente en La moral social y el Tratado de sociología, según Antonio Avelino García. ${ }^{13}$ Con respecto a la diferenciación entre imperialismo geográfico e imperialismo cultural, me permito citar a Alfredo Morales en su análisis de Mi viaje al sur:

Hostos no se declara anti-americano, ya que admira la devoción científica de los angloamericanos, la demostración estadounidense de que la razón y la libertad son solidarias. La fuerza de cohesión orgánica y la afinidad de la moral de la sociedad del Norte es lo que busca para la sociedad del Sur".14

11 "Ideas filosoficas de Eugenio Maria de Hostos". Revista del Instituto de Cultura Puertorriqueña 95-96 (1987) 63.

12 Eugenio María de Hostos, "Mi viaje al Sur: Del paraíso perdido al porvenir latinoamericano", Revista del Instituto de Cultura Puertorriqueña 95-96 (1987) 56.

${ }^{13}$ Eugenio María de Hostos, "Visión hostosiana de la sociedad dominicana", Revista del Instituto de Cultura Puertorriqueña 95-96 (1987) 30.

14 Alfredo Morales, "La realidad social de Mi viaje al Sur", Revista del Instituto de Cultura Puertorriqueña 95-96 (1987) 44. 
La visión de Estados Unidos que Hostos nos da en "La obra de Lastarria" coincide con su propio sueño de una Federación del Caribe.$^{15} \mathrm{El}$ bosquejo que hace Hostos deja afuera ciertos hechos, de los cuales puede que haya tenido conciencia o no, siendo el principal que las trece colonias eran "racialmente homogéneas" sólo desde la perspectiva anglosajona. Pero una discusión del nacionalismo como precursor inevitable del imperialismo llevaría a otro tipo de análisis. Quiero, en cambio, presentar una doble hipótesis: (a) toda teoría del arte que le asigne a éste una función principalmente social, asociada con el nacionalismo, termina por atrasar el desarrollo de las formas artísticas, ya que toda innovación se percibe como des/orden; ${ }^{16} \mathrm{~b}$ ) Hostos, perteneciendo al campo de las ciencias sociales, entroncado en el positivismo y, de acuerdo a Rojas Osorio, en el idealismo kantiano (Hostos 69), percibe, pero condena, los cambios que llevan a lo que hoy en día se reconoce como el arte moderno.

Hostos señala que "lo característico en el arte es la sujeción, la norma, regla, patrón o molde, dado de antemano y ciegamente seguido sin buscar la razón o el porqué de la regla, norma patrón o molde" (O.C., t. XI, 14), cuando quiere enfatizar que la crítica no es un arte, sino una ciencia y un arte (O.C. 15). La crítica que es un arte/ciencia, dedicada al juicio directo, se relaciona con la ética, cuya meta es la práctica del bien(O.C. 17). En otras palabras, para Hostos, como para Platón, lo bueno y lo bello son una y la misma cosa. Dice Hostos: “... la verdadera critica nunca se separa de la moral y tiene por objetivo continuo la justicia" (O.C. 21). Naturalmente, Hostos reserva sus alabanzas para las ciencias sociales por su capacidad para la crítica" (O.C. 24), cuya finalidad es mejorar la especie y la vida humana (O.C. 25).

Todo lo cual refiere de nuevo a Platón, particularmente al Platón de $L a$ república, documento donde se juzga a las artes sólo en cuanto cumplen alguna función social o no. Hostos divide la crítica de arte en dos tipos: "uno, el examen de lo bello independientemente de lo verdadero y de lo bueno; otro en cuanto útil a la cultura y al bien de los humanos" $(O . C ., 25)$, añadiendo: "Los que cultivan el segundo género de crítica contribuyen de una manera mucho más activa al fin moral porque reconocen y declaran que no es bello más que lo que es bueno y que sólo en lo verdadero puede haber tipos de belleza de gracia o de sublimidad" (O.C.,25-26). La función censora de la crítica queda expuesta:

\footnotetext{
${ }^{15}$ Eugenio María de Hostos, Obras completas, Tomo XI: Crítica (San Juan de Puerto Rico: Instituto de Cultura Puertorriqueña, 1969) 287. De ahora en adelante, se hará referencia a este volumen por O.C.

${ }^{16}$ A este respecto, me atengo a los comentarios de Arif Dirlik quien, en "Culturalism as Hegemonic Ideology and as Liberating Practice", Cultural Critique: The Nature and Context of Minority Discourse 6 (Spring 1987) 13-51, señala dos puntos importantes: (a) los intelectuales tercermundistas utilizan la "nostalgia nacionalista" para consolidar su propia hegemonía dentro de las sociedades que habitan;(b)tal culto nostálgico efectivamente los distancia de la realidad contemporánea del tercer mundo.
} 
... importa a la crítica que se aplique del modo más consecuente a descubrir en lo bello lo que es bueno, verdadero y útil, y a condenar por falso e inmoral y peligroso todo arte que desconozca lo bueno, lo verdadero y lo útil (O.C. 26).

Tal condena se justifica porque:

aunque es verdad que la operación intelectual que prevalece en el dominio de las artes es la imaginacion, no se ha de dejar desenfrenada, y bien antes se ha de subordinar al predominio del juicio, de modo que las creaciones artísticas concuerden realmente con las realidades naturales (O.C. 26$).^{17}$

El idealismo de Hostos se evidencia en el hecho de que en ninguna parte describe el tipo humano capacitado para pasar tales juicios sobre la obra de arte; pero lo hemos conocido antes en la persona del filósofo-rey. En términos hostosianos, un individuo, supuestamente empapado de positivismo, aplicando las normas de la razón y la conciencia, puede distinguir entre "buen arte" y "mal arte", condenando a este último. Es lo que Hostos hace en los ensayos que deseo examinar ahora.

El ensayo sobre Teresa Carreño, pianista venezolana, comienza, quizás impropiamente, con una referencia a su "belleza celestial", que Hostos dice no tomar en cuenta para poder juzgar a la artista, no a la mujer (O.C. 32). Su arte, que encuentra sin falla, inspira en él una meditación acerca de los modos de expresión que culmina en una definición totalmente dentro del ámbito del romanticismo europeo:

La música es la voz del sentimiento, lenguaje de la sensibilidad inexpresable, palabra de lo inefable, grito, clamor, exclamación, queja, suspiro de todos los afectos. - Su fin es completar el arte de la palabra articulada, trasponer los límites en que ésta se detiene, llegar con el sonido onomatopéyico a donde no puede llegar el símbolo o la idea, sustituir a la razón en donde la razón es impotente (O.C. 33).

Para ello, necesita encontrar "el medio que reproduzca más recta, más sensiblemente, los caracteres esenciales de un afecto, de una pasión, del

\footnotetext{
${ }^{17}$ Conviene considerar por un momento el impacto que tal vision de arte y de crítica de arte va a tener, en toda Hispanoamérica, en términos de los juicios que se van a pasar utilizando el concepto moral/inmoral-sobre ciertos autores delModernismo. Véanse por ejemplo los desaciertos de Guizado Camacho en el prólogo a las Obras de José Asunción Silva publicadas por la Editorial Ayacucho o el "consenso crítico" sobre la obray la persona de Vargas Vila. Se crea todo un aparato crítico que juzga tanto al arte como al artista de acuerdo a una ideología burguesa, que a veces pasa por marxista, pero quizás haya que preguntarse hasta qué punto el marxismo es otra variante del discurso dominante. Deseo señalar además que, en muchos casos, en el de Silva entre otros, el ataque toma la forma de comentarios sobre la forma que toma la obra de arte.
} 
sentimiento" (O.C., 33). Reed señala que para Hegel la música es la expresión del espíritu puro(Reed 191). Hostos menciona el arpa, el fagot, el oboe, la flauta, el violón, el violín, cuartetos de cuerdas y de vientos, aun la voz humana (O.C. 33-34), pero no soporta el piano.

En cuanto a la voz humana, menciona a Mayerbeer, Donizzetti, Mozart, Bellini, Pacini y Rossini, pero no menciona a Wagner. Hemos visto que Wagner es la figura central en el paso de la música romántica a la música moderna; esto es, de la armonía a la disonancia o tensión musical. Hostos parece repetir las palabras del anónimo crítico de Chopin, aplicándolas al piano: "Para mí, que veo en el piano un instrumento sin personalidad, una asociación infecunda del ritmo sin extensión, sin dilatación, sin vaguedad, sin armonía, sin claroscuro, sin penumbra, sin misterio" (O.C. 35). ¿Y qué es lo que tiene de malola música para piano? -La forma:

La lógica del error como la lógica de la verdad, llega fatalmente a consecuencias terminantes, $y$ en el mecanismo terminante del piano ha llegado hasta donde debe, hasta la confusión del sonido con el ruido, hasta la anulacion de la modulación, convirtiendo el arte del sonido en gimnástica digital, el canto en fraseologia incomprensible" (O.C. 36).

Más tarde menciona "fantasías" para "pianistas-gimnastas cuyo talento artístico no trascendía de la yema de los dedos" (O.C. 36). Por lo tanto, una verdadera artista pierde su tiempo frente al teclado.

Para Hostos, el piano es el órgano musical de la sociabilidad, y sólo puede expresar alegría o melancolía superficiales (O.C. 37). Menciona a Weber, Mozart y Beethoven como compositores para el instrumento, pero no menciona los dos nombres más asociados al piano durante el siglo XIX: Chopin y Liszt, ambos virtuosos "pianistas-gimnastas", para quienes la forma comenzaba a ser de igual o más importancia que el contenido. Hostos revela su prejuicio cuando señala cándidamente: "Yo debiera aborrecer la música porque es un elemento perturbador de la vida reflexiva" o "Cuando se tiene que pensar es incómodo el sentir" (O.C. 40). Su juicio-que otra vez recuerda a Platón-es que la música (en este caso los conciertos Barbieri, 1867) educa el sentimiento pero enerva las fuerzas morales activas (O.C. 40). En la misma reseña, señala que la "Sinfonía Pastoral" es "buena" porque es puramente descriptiva, esto es, objetiva, una observación externa e impersonal de la naturaleza (O.C. 48 ).

De manera que encontramos tres elementos en la crítica musical de Hostos: un rechazo de la forma cuando sospecha que se la puede privilegiar sobre el contenido; desconfianza de la subjetividad; y un juicio evaluativo expresado en términos "morales", pero inscrito por una ideología particular: la ideología de la modernidad científica. Examinemos su crítica de pinturay escultura. En "En la exposición", alaba una estatua de Susana porque el mármol preserva su castidad tal y cómo la describe la leyenda (O.C. 57), regañando a un grupo de damiselas que la evitaban al recordarles que a ellas también se las puede acusar 
de indecentes por los escotes que lucen en las fiestas (O.C. 63). Señala Hostos que lo bello puede ser material o espiritual, pero que siempre la forma es el contenido de la esencia (O.C. 58), definiendo el arte como "La reproducción armónica de la dualidad universal de lo bello" (O.C. 59). Hostos mantiene que el verdadero arte nunca puede ofender la moral; pero resulta que el artista moderno, comenzando con Baudelaire, intenta precisamente ofender la moral, ya que reconoce en el concepto mismo de moralidad un instrumento ideológico utilizado por la burguesía para consolidar su poder hegemónico.

Cuando escribe acerca de la estatua de Caupolicán, Hostos expande su definición de arte:

Enemigo del error como es el arte, yo no he podido nunca considerarlo como hecho individual y tengo una irrefrenable propensión a contemplarlo como fenómeno social ... poesía o pintura, estatuaria o arquitectura, corresponde ante mi juicio a desarrollos de la vida social, y es más un fenómeno biologico de las sociedades que expresion de una vocacion o de una genialidad individual (O.C. 70). ${ }^{18}$

Una vez más encontramos la metáfora orgánica que separa las dos modernidades. Hostos critica a Pedro Lira porque sus paisajes parecen estar compuestos de "partes diferentes" - les falta unidad, la unidad científica de la naturaleza (O.C. 79-80). Por otro lado, alaba a un pintor costumbrista de apellido Caro porque captura "escenas de la vida social" (O.C. 85-86). La contemplación de un cuadro religioso lleva a Hostos a rechazar la religión como invento de la imaginación (O.C. 90) y a afirmar que "lo absoluto" no puede ser confirmado o negado; sólo puede percibirse a través de la ciencia y la razón $(O . C$., 90). El ensayo termina en una nota curiosa: le parece a Hostos que ha sido demasiado inflexible con lo que percibe como un arte incipiente, al que corresponde un tipo de crítica más didáctica, no la suya, hecha como está "en nombre de principios abstractos de la estética, en nombre de la historia crítica, en nombre de la ciencia social" (O.C. 103).

Quedan por examinar algunas reseñas de poesía. En el ensayo sobre el poeta argentino Carlos Guido Spano, lo primero que resalta es la incomodidad que a Hostos le produce el erotismo como sujeto artístico; aclara que Hojas al viento (1871) contiene unos cuantos poemas "del género erótico malsano"; lo que molesta es que a través de la forma Guido Spano intenta expresar efectos sexuales (O.C. 201). El pudor de Hostos es característico de la manipulación de la moral por parte de la clase media para establecer su dominio, de acuerdo a George L. Mosse. Hostos bosqueja su programa poético: el poeta debe cantar

${ }^{18}$ Con esta definición, Hostos se coloca abiertamente en las filas de la modernidad "cientifica". Hay que estudiar el impacto que definiciones como ésta tienen sobre el arte que se crea en la época, y en el aparato crítico que aún hoy en día se apoya en premisas tales. 
lo que es bello, bueno y justo -la vida doméstica, el valor del trabajo, la naturaleza y la patria (O.C. 192). He aquí el discurso dominante de la burguesía, del cual Hostos es el portador (quizás) inconsciente. Favorece una poesía histórica del contenido sociopolítico - sus teorías artísticas parten del Zeitgeist del nacionalismo anglogermánico. La palabra "enervante" aparece una vez más cuando Hostos alude a los pasajes en los que Guido describe la naturaleza parte de la metáfora orgánica es la creencia de que la debilidad moral se manifiesta como condición nerviosa. ${ }^{19}$

Encuentro significativo que Hostos escoja transcribir completo el poema que Guido escribe a su madre - porque comienzo a sospechar que su tan mentado "feminismo" también se encuentra entroncado a un proyecto social cuya meta es asignar a la mujer tareas burguesas-- papeles que ya jugaban y de los cuales ya algunas intentaban liberarse. Hostos comenta: "No hay nada más digno de una madre que un hijo amante de la patria" (O.C. 207); en verdad noble sentimiento, la mujer como productora de guerreros para la patria. Conceptos como éste son de doble filo: dentro de un marco histórico, tienen sentido; fuera de ese contexto, llevan a los fascismos del siglo XX, a Argentina, Cuba o Chile.

En su reseña de Guillermo Matta, Hostos una vez más enfila sus cañones contra el culto de la forma, señalando que por culpa de tal culto la poesía y la literatura de su momento no son lo suficientemente didácticas; el culto a la forma precede el culto a la razón (O.C. 213). Alaba a Matta porque su poesía contiene "el amor de la ciencia ... la adoración de la justicia ... la reverencia del trabajo, la industria, el progreso, la civilización y ... cuantas formas tiene en nuestro tiempo el ideal de la existencia humana" (O.C. 219). Critica a José Joaquín Pérez, poeta dominicano, porque no está a la altura de lo que Hostos espera de él: que por nacionalismo se mueva de la lírica a la épica (O.C. 225); y de que no utilice la forma propia de ésta: el romance (O.C. 230). Tal crítica contrasta con las alabanzas extravagantes que derrama sobre Salomé Ureña de Henríquez, también dominicana, a quien Hostos llama "sacerdotisa del verdadero patriotismo" (O.C. 242). El estilo de tal sacerdotisa se caracteriza por un "lenguaje severo, tono elevado, sentimientos profundos" (O.C. 243). Hostos la canoniza en su triple sacerdocio como maestra, poeta y madre (O.C. 244), la mistificación de la maternidad siendo un componente esencial del discurso dominante. El magisterio femenino es parte de la estrategia de Hostos para educar a las masas; pero visto de otra forma, se puede afirmar que el papel de la mujer dentro de tal proyecto es socializar a las masas para que internalicen

\footnotetext{
19 Mosse, Nationalism and Sexuality, 36. Negros, homosexuales, judíos y mujeres son acusados de "degeneración" - esto es, de sufrir una nerviosidad innata. Sugiero que Hostos conocía la ciencia de la época tal y, como ésta, servia los intereses del grupo que establecía, hegemonicamente, la burguesía. La alianza entre ciencias sociales y medicina lleva a un holocausto en Europa y a otro, que todavia continua, en Hispanoamérica.
} 
el discurso de la clase media. Como poeta, Ureña es el ideal porque, según Hostos, es una "poetisa-patriota" (O.C., 244). Se enfatiza la respetabilidad burguesa al mencionar al esposo y a los hijos; no es, después de todo, una Mary Shelley, una George Sand o una Manuelita Sáenz. Es una mujer que llena a perfección el ideal masculino de lo que el ente femenino debe ser, dentro de una particular ideología operante.

El discurso hostosiano refleja los términos de la ideología de la emergente burguesía decimonónica, de la misma forma en que el discurso de las ciencias sociales que lo informa sobrevive dentro de la cultura hispanoamericana, donde ha causado bastante daño al desarrollo de la modernidad artística. Pero, en el caso de Hostos, no ocurre una inscripción consciente, en el sentido de que, reaccionando ante una determinada circunstancia histórica, Hostos escoge abanderarse con la noción de "progreso" sin tomar conciencia de la ideología que crea tal noción como instrumento para llegar a una meta específica, en este caso un imperialismo cultural. En términos de estética, Hostos favorece la modernidad científica. Nunca sabremos si leyó a Baudelaire, Verlaine o Wilde, si escuchó a Wagner o si se familiarizó con el impresionismo - y, si lo hizo, qué pensaba de ellos. ${ }^{20}$ Era primariamente un educador y un científico social. Pero creo que Hostos encuentra su propio contradiscurso moderno a través de la descripción de su confrontamiento con Hispanoamérica en $M i$ viaje al sur, cuando descubre una totalidad cultural, no como mistificación histórica, sino como una realidad casi intolerable, y señala abiertamente la posible corrupción de la semilla histórica. Tal postura niega la historia oficial, tal y como este ensayo intenta hacerlo y por lo tanto pasa a ser una postura contradiscursiva. Es lo próximo que estudiaré.

${ }^{20}$ Habrá quien arguya que, porque considero el conocimiento de estos individuos y los movimientos que representan indispensable para entender y analizar las premisas de la modernidad artística, estoy "culturalmente colonizado", como Camacho Guizado dice de Jose Asunción Silva. Respondo que la mayoría de los críticos ignoran la historia de las ideas como trasfondo a la crítica literaria, partiendo en cambio de estructuras fosilizadas y de ideologias operantes. En todo caso, la idea de las "dos modernidades" aparece ya en 1977 en el volumen de Matei Calinescu, Five Faces of Modernity: Modernism, AvantGarde, Decadence, Kitsch, Postmodernism (Durham: Duke University Press, 1987, 2a. edicion); ver capitulo titulado "The Two Modernities", 41-46. 